\title{
The molecular evolutionary dynamics of the vomeronasal receptor (class 1) genes in primates: a gene family on the verge of a functional breakdown
}

\author{
Anne D. Yoder * and Peter A. Larsen \\ Department of Biology, Duke University, Durham, NC, USA
}

\section{Edited by:}

Ignacio Salazar, University of

Santiago de Compostela, Spain

Reviewed by:

Alino Martinez-Marcos, Universidad de Castilla, Spain

Robert Anholt, North Carolina State University, USA

*Correspondence:

Anne D. Yoder, Department of Biology, Duke University, Biological Science Building, Science Drive, Box 90338, Durham, 27708 NC, USA

e-mail: anne.yoder@duke.edu
Olfaction plays a critical role in both survival of the individual and in the propagation of species. Studies from across the mammalian clade have found a remarkable correlation between organismal lifestyle and molecular evolutionary properties of receptor genes in both the main olfactory system (MOS) and the vomeronasal system (VNS). When a large proportion of intact (and putatively functional) copies is observed, the inference is made that a particular mode of chemoreception is critical for an organism's fit to its environment and is thus under strong positive selection. Conversely, when the receptors in question show a disproportionately large number of pseudogene copies, this contraction is interpreted as evidence of relaxed selection potentially leading to gene family extinction. Notably, it appears that a risk factor for gene family extinction is a high rate of nonsynonymous substitution. A survey of intact vs. pseudogene copies among primate vomeronasal receptor Class one genes (V1Rs) appears to substantiate this hypothesis. Molecular evolutionary complexities in the V1R gene family combine rapid rates of gene duplication, gene conversion, lineage-specific expansions, deletions, and/or pseudogenization. An intricate mix of phylogenetic footprints and current adaptive landscapes have left their mark on primate V1Rs suggesting that the primate clade offers an ideal model system for exploring the molecular evolutionary and functional properties of the VNS of mammals. Primate V1Rs tell a story of ancestral function and divergent selection as species have moved into ever diversifying adaptive regimes. The sensitivity to functional collapse in these genes, consequent to their precariously high rates of nonsynonymous substitution, confer a remarkable capacity to reveal the lifestyles of the genomes that they presently occupy as well as those of their ancestors.

Keywords: olfaction, gene family evolution, positive selection, adaptation, lemurs, draft genomes

\section{INTRODUCTION}

Vomeronasal receptor (Class 1) genes (V1Rs) are one of five independently derived functional classes of chemoreceptor genes in the olfactory system of mammals. Together with vomeronasal receptor (Class 2) genes (V2Rs) and a small family of formyl peptide receptors (FPRs), V1Rs are found clustered within an anatomical structure referred to as the vomeronasal organ (VNO). The two additional classes of receptor, the odorant receptors (ORs) and trace amine-associated receptors (TAARs) are found in the nasal epithelium. All five are G-protein coupled receptors (GPCRs), and as such, have structural features that are shared with other chemosensory genes such as sweet and bitter taste receptors. All GPCRs are structured to detect an enormous variety of extracellular signals, including photons, ions, small organic molecules and entire proteins. The structure of a GPCR can be divided into three parts: the extracellular region, consisting of the $\mathrm{N}$ terminus and three extracellular loops, the transmembrane region (TM), consisting of seven $\alpha$-helices; and the intracellular region, consisting of three intracellular loops and the C-terminal tail. ORs fall into Class A GPCRs wherein the TM regions comprise a consensus "ligand-binding cradle" that constitutes the bottom of the ligand-binding pocket within the TM bundle. The third TM helix (TM3) has a central role as a structural and functional hub (Venkatakrishnan et al., 2013), putatively placing it under very strong purifying selection given the essential nature of its structure and placement to the stability of the ligand-binding cradle (e.g., Herberger and Loretz, 2013). These insights into the structure-function relationships of the GPCRs have thus yielded new perspectives for molecular evolutionary investigations of the types and levels of selective forces as they act on V1R and other chemosensory genes within mammals generally, and in this review, primates specifically.

The olfactory system is divided into two general systems, the main olfactory system (MOS) and the vomeronasal system (VNS), which though derived from non-homologous evolutionary pathways, are intimately related both ontogenetically, sharing similar molecular and cellular processes, and evolutionarily, 
showing similar adaptations to changing ecological scenarios. This system has been referred to as "dual olfaction" (Suárez et al., 2012) and thus lessons learned from one can reasonably be applied to the other. This view therefore differs from the so-called "differential tuning" hypothesis proposed by Grus and Zhang (2008) in which the authors make note of the fact that though functioning within a single morphological and behavioral system, the MOS and VNS are putatively under different selective regimes with the MOS tuned to environmental and volatile odorants and the VNS to non-volatile semiochemicals that govern many conspecific (e.g, mating) and heterospecific (e.g., predation) interactions. Evidence continues to accumulate that the VNS is finely tuned to social cues and thus under strong lineage-specific selection (e.g., Garrett and Steiper, 2014) and is changing more rapidly than the more conserved ORs (D'Oliveira Albanus et al., 2014). It has been further demonstrated that within the VNS, the two receptor types, V1Rs and V2Rs, derive from different evolutionary precursors with each receptive to different ligand types: V1Rs tuned to detect small chemicals and V2Rs to detect proteinaceous ligands (Giorgi et al., 2000; Leinders-Zufall et al., 2000, 2009; Pantages and Dulac, 2000; Rodriguez et al., 2000; Kouros-Mehr et al., 2001; Del Punta et al., 2002; Giorgi and Rouquier, 2002; Grus and Zhang, 2004; Grus et al., 2005, 2007; Nodari et al., 2008; Korsching, 2009; Haga et al., 2010; Isogai et al., 2011; Park et al., 2011; Wynn et al., 2012; Hohenbrink et al., 2012a, 2014; Haga-Yamanaka et al., 2014).

Though it has been proposed that a move from an aquatic to terrestrial lifestyle has driven an apparent shift from a predominantly V2R to V1R system in mammals, recent investigation of VR gene expression in snakes and lizards has overturned this hypothesis (Brykczynska et al., 2013). This study found that snakes and lizards retain an extremely limited number of V1R genes but exhibit a large number of V2R genes, including multiple lineages of reptile-specific and snake-specific expansions. Moreover, elegant in vivo work by Isogai et al. (2011) has shown that both receptor families are highly active in mice (Chamero et al., 2011). Collectively, the olfactory system allows for the detection of a multitude of odorants and pheromones that are environmentally transmitted and must be internally processed to identify everything from appropriate food sources to potential mates to predators. In short, this sensory system is critical for the survival of the individual and for the propagation of the species.

\section{"THE DARK MATTER OF SOCIAL NEUROSCIENCE"}

In a review of the role of oxytocin and vasopression in modulating social interactions and affilicative behavior among mammals, Insel (2010) adopted the term "dark matter" of social neuroscience to describe the "complex territory between perception and action" that governs social cognition. This conceptual framework also applies broadly to the olfactory system (Chamero et al., 2012). Olfaction is critical to an organism's ability to survive, though in primates, there are multiple clues from anatomy, behavior, and the genome to suggest that the sensitivity of the system has diminished over their evolutionary history (Heymann, 2006; Dong et al., 2009), especially within the anthropoid primates. This decay of the olfactory system in catarrhine primates specifically was initially thought to be linked to the acquisition of trichromatic vision in old world monkeys and apes. In large part, this conclusion was supported by the observation that the howler monkey, the only New World monkey to possess trichromatic vision, showed a much higher proportion of OR pseudogenes than other NW monkeys (Gilad et al., 2004). More complete characterization of the ratio of intact to pseudogene copies and their distributions in both OW and NW anthropoids has overturned this conclusion, however (Gilad et al., 2007; Matsui et al., 2010).

In mammals more generally, numerous studies have found a remarkable connection between organismal lifestyle and molecular evolutionary patterns among olfactory receptors within the MOS and the VNS (Chamero et al., 2012; Ibarra-Soria et al., 2014; Sánchez-Andrade and Logan, 2014). In the case of the VNS, the fit between organismal lifestyle and genomic repertoire is interpreted to relate to pheromonal communication between "emitter" and "receiver". Sex pheromones in particular play fundamental roles in mate choice in a system that is conserved across the animal kingdom (Gomez-Diaz and Benton, 2013; Petrulis, 2013a,b; Liberles, 2014). Recent studies in the mouse model have shown that both the VNO and MOS are key to mediating social behavior (Mandiyan et al., 2005; Chamero et al., 2012) with in vivo studies of specific receptor function revealing an extraordinary specificity of receptor response to specific stimuli (Isogai et al., 2011). The latter study in particular was able to characterize the stimulus-response profiles in $88 \mathrm{VNO}$ receptors, finding a mix of conspecific and heterospecific associations. The results illustrate a fascinating combination of specificity and generality. Whereas some receptors were exquisitely tuned to stimuli from conspecifics (e.g., certain receptors responded only to stimuli from conspecific females) or to heterospecific cues (e.g., some showed a unique association with distinct classes of predators such as snakes, but not others, such as fox), others were much more generalized. Notably, Isogai et al. (2011) found fundamental functional differences between the two classes of VRs, with V1Rs being the more generalized and V2Rs the more specialized. Due to their ability to distinguish among distinct structural classes of steroids, the authors surmised that V1Rs are uniquely geared to detect the physiological status of an individual, whether conspecific or heterospecific. Taken as a whole, the increasing sophistication of studies focused on VNO function reveals a field poised for an explosive era of discovery by uniting and reciprocally illuminating the fields of neuroendrochrinology, neuroimmunology, neuroethology, and social behavior. This integrative approach holds tremendous promise for unlocking the secrets of what Insel (2010) has called "the dark matter of social neuroscience" (Chamero et al., 2012).

\section{A MOLECULAR-EVOLUTIONARY LOCOMOTIVE}

In a landmark study of the V1R genes in mammals, Young et al. (2010) found remarkable patterns of both inter- and intraspecific variability among mammalian genomes, as mined from draft genomes available at that time. They discovered patterns wherein species-specific subfamilies and "semi-private" alleles are common among the 37 mammals sampled with approximately $80 \%$ of V1R clades being species-specific. These molecular evolutionary complexities in the V1R gene family have been 
repeatedly noted and hypothesized to differentially combine rapid rates of gene duplication, gene conversion, lineage-specific expansions, deletions, and/or pseudogenization (e.g., Rodriguez et al., 2002; Shi et al., 2005; Wynn et al., 2012; Brykczynska et al., 2013). This behavior is in keeping with patterns of gene family evolution in general. Demuth et al. (2006) has described the genomic "revolving door" of gene loss and gain that seems to characterize much of the human genome, as well as mammalian outgroups. In their comparison of human, chimp, mouse, rat, and dog, these authors found shifting patterns of expansions and contractions within the nearly 10,000 gene families compared by the study. Regarding primate evolution specifically, their study indicates that the human genome contains at least 1418 genes $(6.4 \%$ of all known genes at that time) that do not have orthologs in the chimpanzee, with an even greater discrepancy found between mouse and rat. The authors raise the interesting point that duplication and losses within gene families have played a greater role than nucleotide substitution in generating evolutionary change across mammalian genomes, and in the human genome specifically.

The question thus arises: what are the forces that drive this molecular evolutionary locomotive? An obvious dichotomy to be considered is between neutral and adaptive processes (e.g., Demuth et al., 2006; Park et al., 2011; Wynn et al., 2012). The phylogenetic distribution within and among mammals for both ORs and VRs suggests a strong role for adaptation, both as individual gene classes (e.g., Shi et al., 2005; Verrelli et al., 2008; Luca et al., 2010; Matsui et al., 2010; Wang et al., 2010a,b; Yoder et al., 2014) and in concert with one another (Suárez et al., 2012). These patterns extend broadly across the animal kingdom. In a study that surveyed chemosensory signals and their receptors in the olfactory system of mice, insects, and nematodes, Ihara et al. (2013) review the current understanding of signaling molecules where the information stream from receptor to specific behavior has been characterized. They find an overarching pattern wherein each organism has evolved a chemosensory system that ideally suits its lifestyle or environmental conditions. Given their focus on model organisms, these authors were able to examine the precise molecular mechanisms that underlie the linkage from signaling mechanisms to behaviors. Another study of in vitro responses in the ORs of mouse and human found a high fidelity of OR orthologs in primates and rodents, demonstrating that amino acid changes can have dramatic functional consequences that are a reflection of niche and other species-specific demands (Adipietro et al., 2012). For non-model organisms, however, the correspondence among environment, genome, and behavior must be approximate and correlative.

In most cases, conclusions about relative adaptive fit of $\mathrm{OR}$ and VR repertoires have been drawn from the molecular characterization of intact vs. pseudogene copies within receptor classes (e.g., Lane et al., 2002; Rodriguez et al., 2002; Pfister and Rodriguez, 2005; Shi et al., 2005; Young et al., 2005; Liman, 2006; Niimura and Nei, 2006; Grus et al., 2007; Young and Trask, 2007; Olender et al., 2008, 2012; Johnstone et al., 2009; Nikaido et al., 2013). Specifically, when there is a large proportion of intact vs. pseudogene copies, the inference is made that a particular mode of chemoreception is critically linked to the organism's lifestyle and is thus under strong positive selection. Conversely, when the receptors in question are found to have a disproportionately large number of pseudogene copies, investigators interpret this as evidence of relaxed selection and concomitant drift in nucleotide substitutions. As a classic example of such inference, Gilad et al. (2004) interpreted the deterioration of the OR repertoire in Old World monkeys and apes (including humans) to have a functional correspondence with the acquisition of trichromatic vision in these but not other primates. Similarly, Zhao et al. (2011) interpreted the deterioration of the VNS in bats to be related to the acquisition of their novel communication and foraging system (although based on a limited sample). Numerous studies have noted a connection between nocturnality and a high proportion of intact VR genes (e.g., Wang et al., 2010a,b) based upon the assumption that nocturnal habits will place strong selective pressures on the olfactory system in lieu of the visual system.

Expansion and contraction in gene family evolution is likely universal in eukaryotes. In a detailed study of gene family histories in yeast, Ames et al. (2014) observed differential rates of both phenomena among and between gene families and species, finding that both appear to be correlated with speciesspecific adaptations. Moreover, this study found that gene families with highly specific functions (as would be the case with chemosensation) repeatedly and independently expanded in multiple species, thus suggesting common underlying adaptive pressures. Within the human lineage, at least $2.7 \%$ of the genome has been uniquely duplicated since the human-chimp divergence, undoubtedly reflecting many of the unique adaptations of the human lifestyle. Similarly, gene loss has also been proposed as an adaptive response to changing environmental conditions or adaptive strategies (Olson, 1999) though contraction has been more typically assumed to reflect a relaxation of selective pressure (e.g., Liman and Innan, 2003; Mundy and Cook, 2003; Mundy, 2006; Zhao et al., 2011).

The effects of positive selection are more easily conceived for expansion via gene duplication with subsequent amino acid changes to the newly duplicated gene. As an example, positive selection may be exerted on regions of a receptor gene where that receptor manifests its ligand-binding functions. If the sequence change expands the repertoire of chemosensory signals that can be detected, it follows that this will be advantageous to the organism and these changes will be fixed by positive selection. One possible example of this phenomenon can be inferred from a recent empirical study of the V1R gene family in strepsirrhine primates (the lemurs and lorises). In that study, the authors discovered a remarkable expansion of V1R genes in the strepsirrhines relative to other primates, finding a gene subfamily putatively unique to the strepsirrhine clade and designated as V1Rstrep (Yoder et al., 2014). Moreover, phylogenetic analysis of V1Rstrep revealed that a relatively ancient ( $>40$ mya) gene duplication occurred within the lemur clade, resulting in two V1Rstrep subclades referred to as $\alpha$ and $\beta$. Presumably, this pattern of initial expansion followed by gene duplication and further expansion has conferred a functional advantage to the lemurs, a finding that is congruent with experimental work that has shown that orthologs are far more likely to correspond to a common odor than will paralogs within the same gene family (Adipietro et al., 2012). 


\section{V1Rs WITHIN THE PRIMATES: ON THE VERGE OF A FUNCTIONAL BREAKDOWN}

As with most mammals, the phylogenetic relationships among primate V1Rs do not closely follow those of the species that carry them. In other words, there is a significant mismatch between the V1R gene tree and the primate species tree. Both Table 1 and Figure 1 illustrate the phylogenetic patterns among all primate V1Rs mined from (predominantly) draft genomes available in Ensembl as of 2010 (Young et al., 2010). The figure on the left (A) illustrates the accepted primate species phylogeny whereas that on the right (B) illustrates the primate V1R gene tree. Figure 1 establishes both that the ancestral primate genome carried at least six subfamilies of V1R alleles, and that the strepsirrhines (illustrated in shades of blue) have a substantially higher number of copies than do the haplorrhines (all other colors). The figure thus illustrates differential patterns of expansion and contraction in the V1R system during primate evolutionary history.

Changes in gene family copy number among species can evolve at rapid rates (e.g., Cutler et al., 2007; She et al., 2008). Indeed, comparisons among inbred strains of laboratory mice have revealed similar patterns within the V1R complex, further supporting the idea that rates of change can be very high for chemosensory genes (Wynn et al., 2012). It is noteworthy that one of the common "symptoms" of gene family extinction is a high rate of nonsynonymous substitution (Nielsen et al., 2005). As a specific case, Wynn et al. (2012) observed that 57\% of total single-nucleotide polymorphisms (SNPs) in the VRs of mice are
Table 1 | Number of total and intact V1Rs identified by Young et al. (2010) in primate species

\begin{tabular}{lcc}
\hline \multicolumn{1}{c}{ Species } & Total V1Rs* & Intact V1Rs \\
\hline Macaque & 60 & 0 \\
Gibbon & 110 & 2 \\
Gorilla & 115 & 3 \\
Human & 116 & 3 \\
Baboon & 94 & 3 \\
Chimpanzee & 106 & 4 \\
Orangutan & 178 & 5 \\
Marmoset & 63 & 8 \\
Tarsier & 266 & 42 \\
Bushbaby & 133 & 78 \\
Mouse lemur & 259 & 214 \\
\hline
\end{tabular}

* Values are median estimates (Young et al., 2010).

nonsynonymous substitutions for both wild populations and for inbred laboratory strains. The relationship between nonsynonymous and synonymous substitution rates has long been used as a measure for estimating the strength and directionality of selection (i.e., purifying vs. positive). Referred to as the $\mathrm{dN} / \mathrm{dS}$ rate ratio, this measure has served as a reliable (though approximate) method in studies across virtually all of metazoan life (Yang, 1998; Vamathevan et al., 2008; Yang et al., 2009; Yang and dos Reis, 2011) and is applicable to primate VRs (Shi et al., 2005; Hohenbrink et al., 2012b; Yoder et al., 2014). One consequence of this positive selection engine is that the pairwise genetic
A

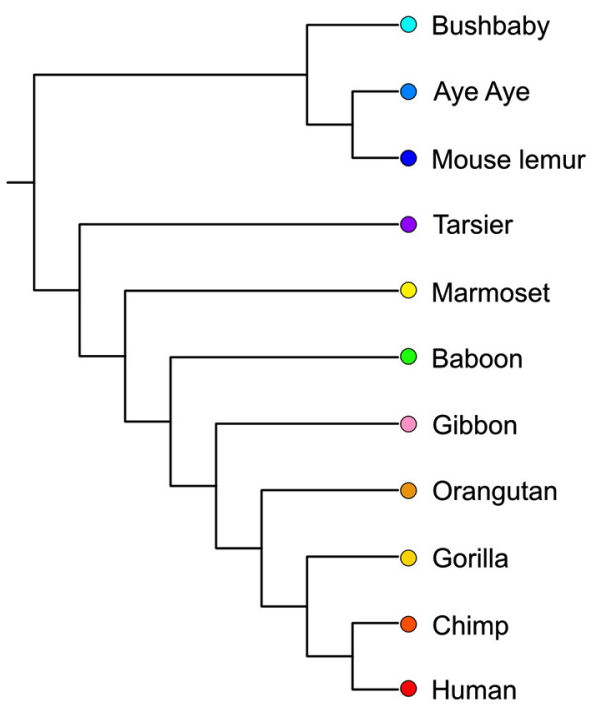

B

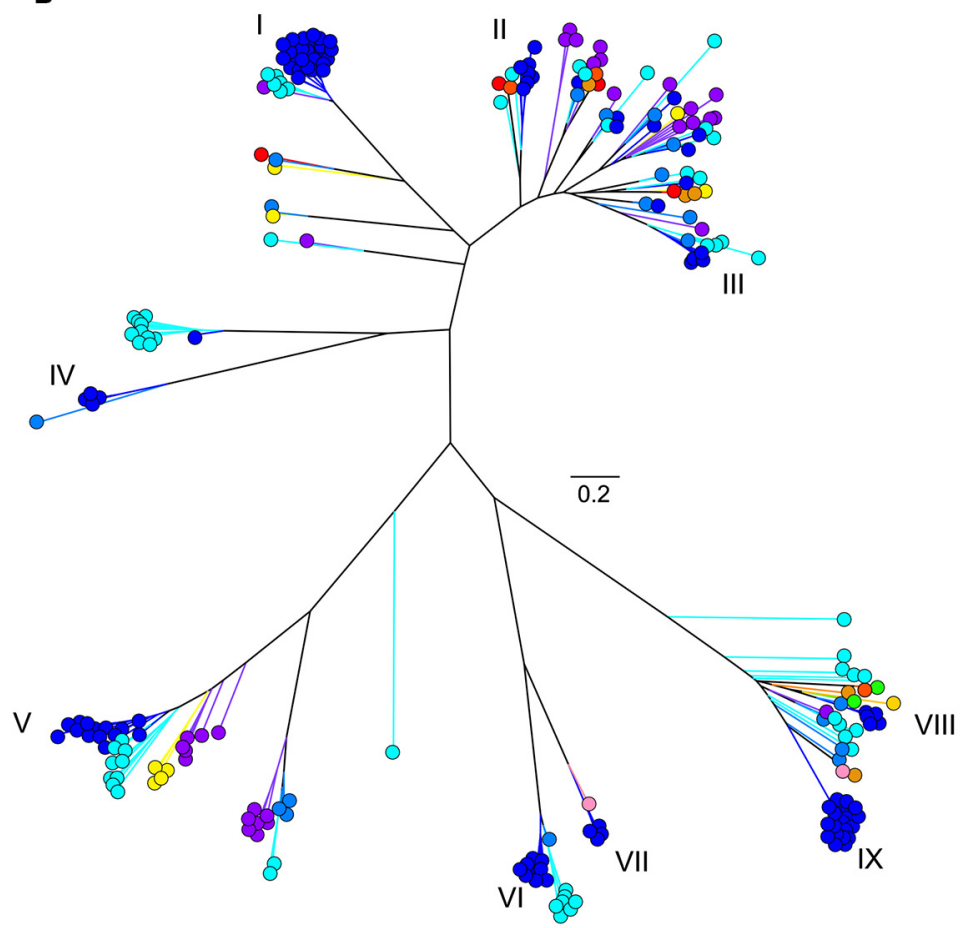

FIGURE 1 | (A) Phylogeny of primate species discussed herein. (B) Unrooted maximum likelihood tree generated from RAxML analyses of primate V1R amino acid sequences. Roman numerals identify mouse lemur V1R subfamilies described in Hohenbrink et al. (2012b). 
distances among amino acids can be greater than their underlying nucleotide distances (e.g., see Table 1 in Yoder et al. (2014); whereas pairwise nucleotide distances tend to range up to a maximum of $13 \%$ in that study, those for amino acids can exceed $26 \%)$. It therefore stands to reason that these high rates of amino acid change must place VRs on the verge of functional collapse. Even the slightest relaxation of selective pressure can tip the balance towards pseudogenization and gene family contraction. In the words of Liman $(2006,2012)$ it is a "use it or lose it" system.

A survey of the number of intact copies among the primates appears to substantiate this hypothesis (Figure 2; Table 1). Whereas the two strepsirrhines (mouse lemur and bushbaby) for which draft genomes exist show a preponderance of intact copies, the converse is true for the haplorrhine primates surveyed. In some cases, the lack of intact copies is complete, as in the macque, which shows zero intact copies (Table 1). Notably, some of the haplorrhine primates show a high number of copies overall, though the vast majority are pseudogenes (e.g., orangutan). This overall pattern is both phylogenetically and anatomically correlated. The strepsirrhine/haplorrhine divergence occurred at least
60 mya (Yoder and Yang, 2000, 2004; Poux and Douzery, 2004; Wilkinson et al., 2011; Springer et al., 2012), and is also reflected in the very different anatomies of the olfactory apparatus in the two primate groups. Indeed, the word "strepsirrhine" refers to the sinuous or "comma-shaped" nostrils of lemurs and lorises while "haplorrhine" refers to the simple or "single-fold" nostrils of tarsiers, monkeys and apes.

\section{THE EVOLUTIONARY FOOTPRINTS OF ANCESTORS AND THEIR DESCENDANTS}

An intricate mix of phylogenetic footprints and current adaptive landscapes have left their mark on primate V1Rs suggesting that the primate clade offers an ideal model system for exploring the molecular evolutionary and functional properties of the VNS of mammals. The primate phylogeny is neatly divided into halves, with the haplorrhines on one side and the strepsirrhines on the other. And whereas the haplorrhines show anatomical and behavioral characteristics that reflect their reliance on vision over olfaction, the opposite is true of the strepsirrhines. Of all extant primates, the strepsirrhine primates are renowned for their

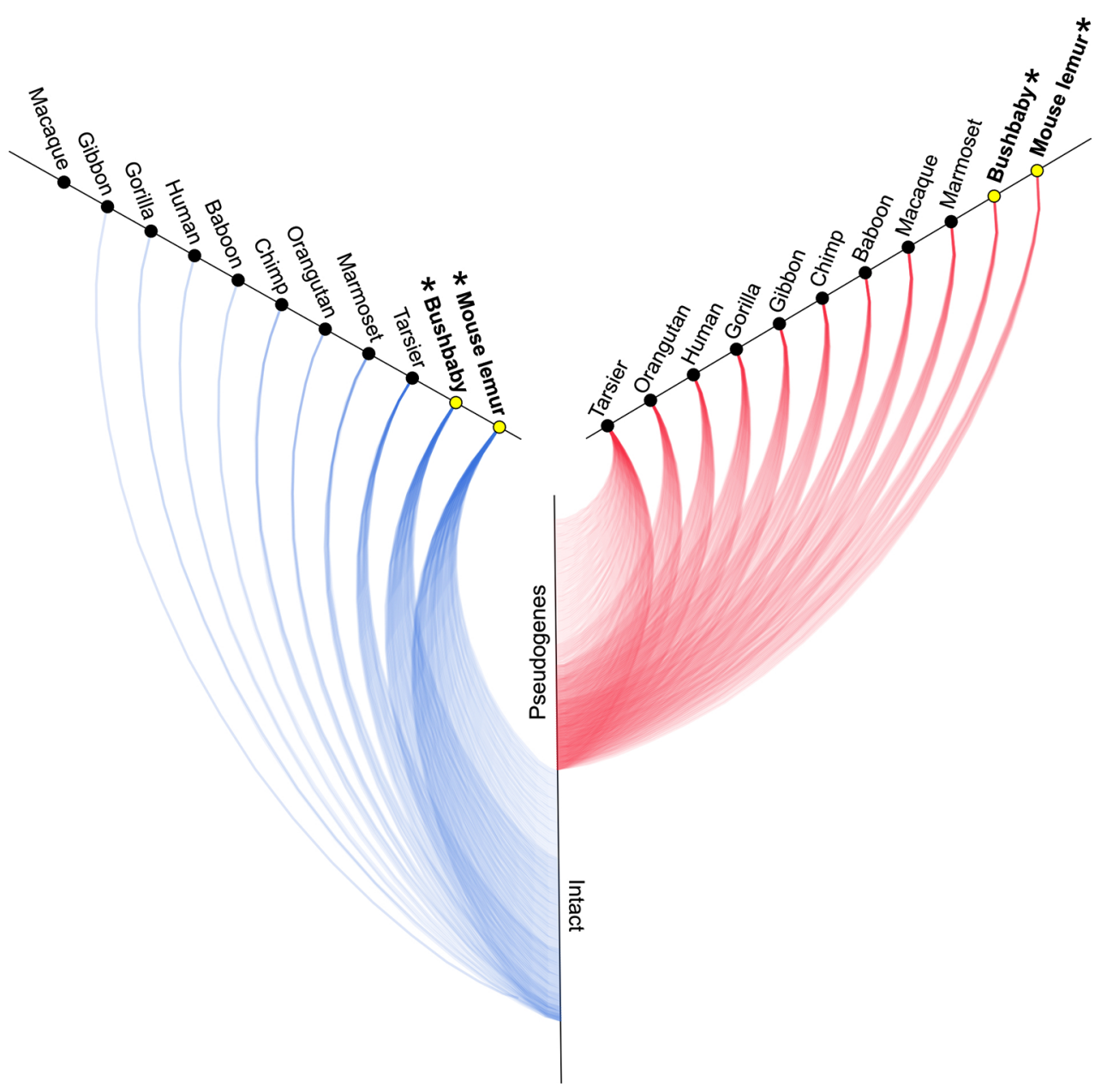

FIGURE 2 | Hive plot showing approximate number of intact (blue lines) and non-functional (red lines) V1R genes identified by Young et al. (2010) in primates (see Table 1). Asterisks and yellow circles identify strepsirrhine primates. See Table 1 for exact counts of gene copies. 
complex patterns of scent marking and other modes of olfactory communication (Schilling et al., 1990; Perret and Schilling, 1995; Perret, 1996, 2005; Kappeler, 1998; Perret et al., 2003; Suendermann et al., 2008; Boulet et al., 2010; Charpentier et al., 2010; Crawford et al., 2011; Delbarco-Trillo et al., 2011; Kappel et al., 2011; Rushmore et al., 2012). Moreover, all members of the Strepsirrhini retain the ancestral characteristic of a wet nose, typical of many mammals.

As might be predicted, haplorrhines show a V1R system that is notably diminished both in terms of copy number and in terms of intact vs. pseudogene copies with the converse being true of the strepsirrhines (Figure 2; Table 1). Though this functional anatomical division has often been attributed to a shift from a nocturnal lifestyle in the ancestral primate to a diurnal one in the vast majority of haplorrhine primates (excepting only the living tarsiers and the monotypic owl monkey, genus Aotus), causality is unlikely to be that simple. Not only are the circadian habits of the ancestral primate currently debated, the intensive study of V1Rs in strepsirrhine primates has revealed a system in which history (i.e., phylogeny) appears to trump present-day lifestyle. Namely, diurnal strepsirrhines were found to have V1R systems that are equally elaborate to those of nocturnal strepsirrhines (Yoder et al., 2014). It is here worth noting, however, that our survey of primate V1Rs as illustrated in Figure $\mathbf{2}$ and Table $\mathbf{1}$ depend in large part on, and by necessity, on bioinformatic mining from draft genomes (Young et al., 2010). When more targeted sequencing approaches are implemented, we find that allele counts in draft genomes may be dramatically underestimated (Larsen et al., 2014; Figure 3). These findings are consistent with those from other mammalian groups. For example, Wynn et al. (2012) expanded the number of known mouse VR alleles by more than nine fold by employing massively parallel sequencing methods for VR genomic characterization. Even so, these authors noted that even though these methods were capable of accurately resolving more than half of mouse VRs, they also concluded that copy number variation and non-specific short read mapping compromise complete repertoire analysis. Clearly, much remains to be learned about the genomic characterization of VRs in primates and other mammals.

\section{CONCLUSIONS}

In this review, we have synthesized information regarding gene family evolution across a broad phylogenetic expanse, spanning yeast to humans. Specifically, we have focused on the molecularevolutionary dynamics of V1R genes in primates. As a result of these comparisons, we conclude that mammalian V1Rs are under extreme pressures for rapid evolution, both at the nucleotide and the amino acid levels. Moreover, these genes have been hypothesized to experience strong positive selection to maintain a diverse repertoire of functional copies when fine-scale and precise pheromonal communication is fundamental to species survival (e.g., predation) and/or propagation (e.g., mating behaviors). Alternatively, when other sensory systems such as vision are more dominant, positive selection is relaxed and the proportion of functional copies rapidly deteriorates, putatively due to the high rates of nonsynonymous substitution at the nucleotide level.

The distribution of intact to pseudogene copies in primates appears to bear out these assumptions. Whereas haplorrhine

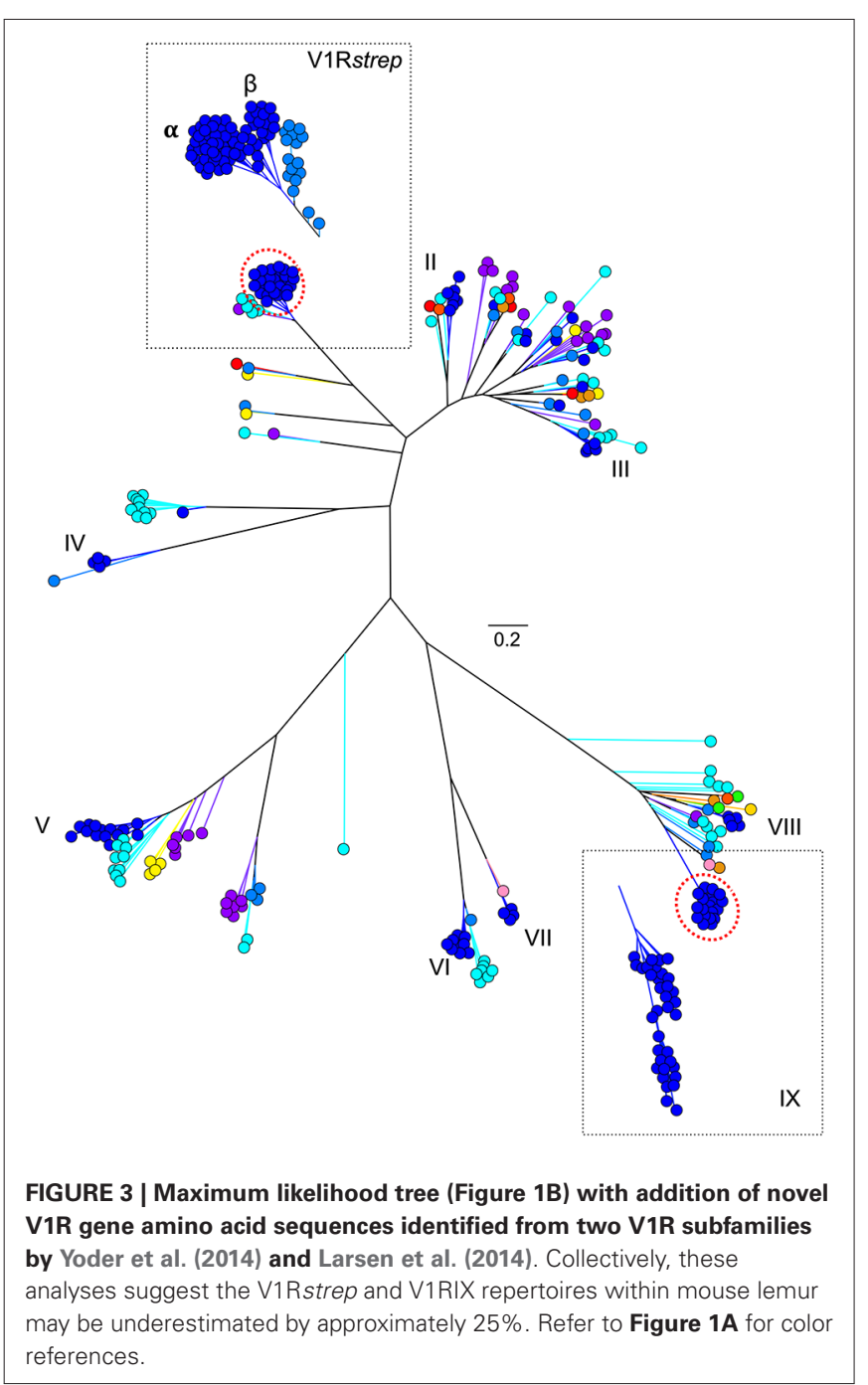

primates with their anatomically diminished olfactory systems show very few intact V1Rs, strepsirrhines with their ancestrallyretained and highly-developed olfactory anatomy show very large repertoires of intact V1Rs. Admittedly, limitations in available genomic resources for primates constrain our ability to draw definitive conclusions. In the near future, however, advancements in DNA sequencing technology (e.g., Pacific Biosciences $R S I I)$ will contribute to more robust primate genome assemblies (Chaisson et al., 2014) and, in turn, will provide more precise measures of gene family diversity, including V1Rs. In the meantime, we contend that the conservative nature of VR copy number estimates and the estimated ratios of intact to pseudogene copies yield patterns that will withstand further scrutiny with enhanced data. Primate V1Rs will likely persist in telling a story of ancestral function and divergent selection as species and clades have moved into ever diversifying adaptive regimes. The sensitivity to functional collapse in these genes, consequent to their precariously high rates of nonsynonymous substitution, confer a remarkable capacity to reveal the lifestyles of the genomes that they presently occupy as well as those of their ancestors. 


\section{ACKNOWLEDGMENTS}

We thank Guest Associate Editors Pablo Chamero and Ignacio Salazar for their invitation to contribute to this special volume on the morphology, genetics and evolution of the mammalian olfactory subsystem. The manuscript was significantly improved thanks to comments from H. Matsunami and from two anonymous reviewers. Anne D. Yoder was supported by a travel grant from Burroughs Welcome during the preparation of this work.

\section{REFERENCES}

Adipietro, K. A., Mainland, J. D., and Matsunami, H. (2012). Functional evolution of mammalian odorant receptors. PLoS Genet. 8:e1002821. doi: 10.1371/journal. pgen.1002821

Ames, R. M., Money, D., and Lovell, S. C. (2014). Inferring gene family histories in yeast identifies lineage specific expansions. PLoS One 9:e99480. doi: 10 1371/journal.pone.0099480

Boulet, M., Crawford, J. C., Charpentier, M. J. E., and Drea, C. M. (2010). Honest olfactory ornamentation in a female-dominant primate. J. Evol. Biol. 23, 15581563. doi: 10.1111/j.1420-9101.2010.02007.x

Brykczynska, U., Tzika, A. C., Rodriguez, I., and Milinkovitch, M. C. (2013). Contrasted evolution of the vomeronasal receptor repertoires in mammals and squamate reptiles. Genome Biol. Evol. 5, 389-401. doi: 10.1093/gbe/evt013

Chaisson, M. J. P., Huddleston, J., Dennis, M. Y., Sudmant, P. H., Malig, M., Hormozdiari, F., et al. (2014). Resolving the complexity of the human genome using single-molecule sequencing. Nature doi: 10.1038/nature13907. [Epub ahead of print].

Chamero, P., Katsoulidou, V., Hendrix, P., Bufe, B., Roberts, R., Matsunami, H., et al. (2011). G protein G(alpha)o is essential for vomeronasal function and aggressive behavior in mice. Proc. Natl. Acad. Sci. U S A 108, 12898-12903. doi: 10.1073/pnas.1107770108

Chamero, P., Leinders-Zufall, T., and Zufall, F. (2012). From genes to social communication: molecular sensing by the vomeronasal organ. Trends Neurosci. 35, 597-606. doi: 10.1016/j.tins.2012.04.011

Charpentier, M. J. E., Crawford, J. C., Boulet, M., and Drea, C. M. (2010). Message 'scent': lemurs detect the genetic relatedness and quality of conspecifics via olfactory cues. Anim. Behav. 80, 101-108. doi: 10.1016/j.anbehav.2010. 04.005

Crawford, J. C., Boulet, M., and Drea, C. M. (2011). Smelling wrong: hormonal contraception in lemurs alters critical female odour cues. Proc. Biol. Sci. 278, 122-130. doi: 10.1098/rspb.2010.1203

Cutler, G., Marshall, L. A., Chin, N., Baribault, H., and Kassner, P. D. (2007). Significant gene content variation characterizes the genomes of inbred mouse strains. Genome Res. 17, 1743-1754. doi: 10.1101/gr.6754607

Delbarco-Trillo, J., Burkert, B. A., Goodwin, T. E., and Drea, C. M. (2011). Night and day: the comparative study of strepsirrhine primates reveals socioecological and phylogenetic patterns in olfactory signals. J. Evol. Biol. 24, 82-98. doi: 10 1111/j.1420-9101.2010.02145.x

Del Punta, K., Leinders-Zufall, T., Rodriguez, I., Jukam, D., Wysocki, C. J., Ogawa, S., et al. (2002). Deficient pheromone responses in mice lacking a cluster of vomeronasal receptor genes. Nature 419, 70-74. doi: 10.1038/nature00955

Demuth, J. P., De Bie, T., Stajich, J. E., Cristianini, N., and Hahn, M. W. (2006). The evolution of mammalian gene families. PLoS One 1:e85. doi: 10.1371/journal. pone. 0000085

D’Oliveira Albanus, R., Siqueira Dalmolin, R. J., Rybarczyk-Filho, J. L., Alves Castro, M. A., and Fonseca Moreira, J. C. (2014). Differential evolutionary constriants in the evolution of chemoreceptors: a murine and human case study. ScientificWorldJournal 2014:696485. doi: 10.1155/2014/696485

Dong, D., He, G., Zhang, S., and Zhang, Z. (2009). Evolution of olfactory receptor genes in primates dominated by birth-and-death process. Genome Biol. Evol. 1, 258-264. doi: 10.1093/gbe/evp026

Garrett, E. C., and Steiper, M. E. (2014). Strong links between genomic and anatomical diversity in both mammalian olfactory chemosensory systems. Proc. Biol. Sci. 281:20132828. doi: 10.1098/rspb.2013.2828

Gilad, Y., Wiebe, V., Przeworski, M., Lancet, D., and Pääbo, S. (2004). Loss of olfactory receptor genes coincides with the acquisition of full trichromatic vision in primates. PLoS Biol. 2:e5. doi: 10.1371/journal.pbio.0020005
Gilad, Y., Wiebe, V., Przeworski, M., Lancet, D., and Pääbo, S. (2007). Correction: loss of olfactory receptor genes coincides with the acquisition of full trichromatic vision in primates. PLoS Biol. 5:e148. doi: 10.1371/journal.pbio.00 50148

Giorgi, D., Friedman, C., Trask, B. J., and Rouquier, S. (2000). Characterization of nonfunctional V1R-like pheromone receptor sequences in human. Genome Res. 10, 1979-1985. doi: 10.1101/gr.10.12.1979

Giorgi, D., and Rouquier, S. (2002). Identification of V1R-like putative pheromone receptor sequences in non-human primates. Characterization of V1R pseudogenes in marmoset, a primate species that possesses an intact vomeronasal organ. Chem. Senses 27, 529-537. doi: 10.1093/chemse/27.6.529

Gomez-Diaz, C., and Benton, R. (2013). The joy of sex pheromones. EMBO Rep. 14, 874-883. doi: 10.1038/embor.2013.140

Grus, W. E., Shi, P., and Zhang, J. (2007). Largest vertebrate vomeronasal type 1 receptor gene repertoire in the semiaquatic platypus. Mol. Biol. Evol. 24, 2153 2157. doi: 10.1093/molbev/msm157

Grus, W. E., Shi, P., Zhang, Y. P., and Zhang, J. (2005). Dramatic variation of the vomeronasal pheromone receptor gene repertoire among five orders of placental and marsupial mammals. Proc. Natl. Acad. Sci. U S A 102, 5767-5772. doi: 10. 1073/pnas.0501589102

Grus, W. E., and Zhang, J. (2004). Rapid turnover and species-specificity of vomeronasal pheromone receptor genes in mice and rats. Gene 340, 303-312. doi: 10.1016/j.gene.2004.07.037

Grus, W. E., and Zhang, J. Z. (2008). Distinct evolutionary patterns between chemoreceptors of 2 vertebrate olfactory systems and the differential tuning hypothesis. Mol. Biol. Evol. 25, 1593-1601. doi: 10.1093/molbev/msn107

Haga, S., Hattori, T., Sato, T., Sato, K., Matsuda, S., Kobayakawa, R., et al. (2010). The male mouse pheromone ESP1 enhances female sexual receptive behaviour through a specific vomeronasal receptor. Nature 466, 118-122. doi: $10.1038 /$ nature09142

Haga-Yamanaka, S., Ma, L., He, J., Qiu, Q., Lavis, L. D., Looger, L. L., et al. (2014). Integrated action of pheromone signals in promoting courtship behavior in male mice. Elife 3:e03025. doi: 10.7554/elife.03025

Herberger, A. L., and Loretz, C. A. (2013). Vertebrate extracellular calcium-sensing receptor evolution: selection in relation to life history and habitat. Comp. Biochem. Physiol. Part D Genomics Proteomics 8, 86-94. doi: 10.1016/j.cbd.2012. 12.004

Heymann, E. W. (2006). The neglected sense-olfaction in primate behavior, ecology and evolution. Am. J. Primatol. 68, 519-524. doi: 10.1002/ajp.20249

Hohenbrink, P., Dempewolf, S., Zimmermann, E., Mundy, N. I., and Radespiel, U. (2014). Functional promiscuity in a mammalian chemosensory system: extensive expression of vomeronasal receptors in the main olfactory epithelium of mouse lemurs. Front. Neuroanat. 8:102. doi: 10.3389/fnana.2014. 00102

Hohenbrink, P., Mundy, N. I., Zimmermann, E., and Radespiel, U. (2012a). First evidence for functional vomeronasal 2 receptor genes in primates. Biol. Lett. 9:20121006. doi: 10.1098/rsbl.2012.1006

Hohenbrink, P., Radespiel, U., and Mundy, N. I. (2012b). Pervasive and ongoing positive selection in the vomeronasal-1 receptor (V1R) repertoire of mouse lemurs. Mol. Biol. Evol. 29, 3807-3816. doi: 10.1093/molbev/mss188

Ibarra-Soria, X., Levitin, M. O., and Logan, D. W. (2014). The genomic basis of vomeronasal-mediated behaviour. Mamm. Genome 25, 75-86. doi: 10 . 1007/s00335-013-9463-1

Ihara, S., Yoshikawa, K., and Touhara, K. (2013). Chemosensory signals and their receptors in the olfactory neural system. Neuroscience 254, 45-60. doi: 10.1016/j. neuroscience.2013.08.063

Insel, T. R. (2010). The challenge of translation in social neuroscience: a review of oxytocin, vasopressin and affiliative behavior. Neuron 65, 768-779. doi: 10 1016/j.neuron.2010.03.005

Isogai, Y., Si, S., Pont-Lezica, L., Tan, T., Kapoor, V., Murthy, V. N., et al. (2011). Molecular organization of vomeronasal chemoreception. Nature 478, 241-245. doi: $10.1038 /$ nature 10437

Johnstone, K. A., Ciborowski, K. L., Lubieniecki, K. P., Chow, W., Phillips, R. B., Koop, B. F., et al. (2009). Genomic organization and evolution of the vomeronasal type 2 receptor-like (OlfC) gene clusters in Atlantic salmon, Salmo salar. Mol. Biol. Evol. 26, 1117-1125. doi: 10.1093/molbev/msp027

Kappel, P., Hohenbrink, S., and Radespiel, U. (2011). Experimental evidence for olfactory predator recognition in wild mouse lemurs. Am. J. Primatol. 73, 928 938. doi: 10.1002/ajp.20963 
Kappeler, P. M. (1998). To whom it may concern: the transmission and function of chemical signals in lemur catta. Behav. Ecol. Sociobiol. 42, 411-421. doi: 10. 1007/s002650050455

Korsching, S. (2009). The molecular evolution of teleost olfactory receptor gene families. Results Probl. Cell Differ. 47, 37-55. doi: 10.1007/400_2008_11

Kouros-Mehr, H., Pintchovski, S., Melnyk, J., Chen, Y. J., Friedman, C., Trask, B., et al. (2001). Identification of non-functional human VNO receptor genes provides evidence for vestigiality of the human VNO. Chem. Senses 26, 1167 1174. doi: 10.1093/chemse/26.9.1167

Lane, R. P., Cutforth, T., Axel, R., Hood, L., and Trask, B. J. (2002). Sequence analysis of mouse vomeronasal receptor gene clusters reveals common promoter motifs and a history of recent expansion. Proc. Natl. Acad. Sci. U S A 99, 291296. doi: 10.1073/pnas.012608399

Larsen, P. A., Heilman, A. M., and Yoder, A. D. (2014). The utility of PacBio circular consensus sequencing for characterizing complex gene families in non-model organisms. BMC Genomics 15:720. doi: 10.1186/1471-2164-15-720

Leinders-Zufall, T., Ishii, T., Mombaerts, P., Zufall, F., and Boehm, T. (2009). Structural requirements for the activation of vomeronasal sensory neurons by MHC peptides. Nat. Neurosci. 12, 1551-1558. doi: 10.1038/nn.2452

Leinders-Zufall, T., Lane, A. P., Puche, A. C., Ma, W., Novotny, M. V., Shipley, M. T., et al. (2000). Ultrasensitive pheromone detection by mammalian vomeronasal neurons. Nature 405, 792-796. doi: 10.1038/35015572

Liberles, S. D. (2014). Mammalian pheromones. Annu. Rev. Physiol. 76, 151-175. doi: 10.1146/annurev-physiol-021113-170334

Liman, E. R. (2006). Use it or lose it: molecular evolution of sensory signaling in primates. Pflugers Arch. 453, 125-131. doi: 10.1007/s00424-006-0120-3

Liman, E. R. (2012). Changing senses: chemosensory signaling and primate evolution. Adv. Exp. Med. Biol. 739, 206-217. doi: 10.1007/978-1-46141704-0_13

Liman, E. R., and Innan, H. (2003). Relaxed selective pressure on an essential component of pheromone transduction in primate evolution. Proc. Natl. Acad. Sci. US A 100, 3328-3332. doi: 10.1073/pnas.0636123100

Luca, F., Perry, G. H., and Di Rienzo, A. (2010). Evolutionary adaptations to dietary changes. Annu. Rev. Nutr. 30, 291-314. doi: 10.1146/annurev-nutr-080508141048

Mandiyan, V. S., Coats, J. K., and Shah, N. M. (2005). Deficits in sexual and aggressive behaviors in Cnga2 mutant mice. Nat. Neurosci. 8, 1660-1662. doi: 10. 1038/nn1589

Matsui, A., Go, Y., and Niimura, Y. (2010). Degeneration of olfactory receptor gene repertoires in primates: no direct link to full trichromatic vision. Mol. Biol. Evol. 27, 1192-1200. doi: 10.1093/molbev/msq003

Mundy, N. I. (2006). Genetic basis of olfactory communication in primates. Am. J. Primatol. 68, 559-567. doi: 10.1002/ajp.20252

Mundy, N. I., and Cook, S. (2003). Positive selection during the diversification of class I vomeronasal receptor-like (V1RL) genes, putative pheromone receptor genes, in human and primate evolution. Mol. Biol. Evol. 20, 1805-1810. doi: 10. 1093/molbev/msg192

Nielsen, R., Bustamante, C., Clark, A. G., Glanowski, S., Sackton, T. B., Hubisz, M. J., et al. (2005). A scan for positively selected genes in the genomes of humans and chimpanzees. PLoS Biol. 3:e170. doi: 10.1371/journal.pbio.0030170

Niimura, Y., and Nei, M. (2006). Evolutionary dynamics of olfactory and other chemosensory receptor genes in vertebrates. J. Hum. Genet. 51, 505-517. doi: 10. 1007/s10038-006-0391-8

Nikaido, M., Suzuki, H., Toyoda, A., Fujiyama, A., Hagino-Yamagishi, K., Kocher, T. D., et al. (2013). Lineage-specific expansion of vomeronasal type 2 receptorlike (OlfC) genes in cichlids may contribute to diversification of amino acid detection systems. Genome Biol. Evol. 5, 711-722. doi: 10.1093/gbe/ evt041

Nodari, F., Hsu, F. F., Fu, X., Holekamp, T. F., Kao, L. F., Turk, J., et al. (2008). Sulfated steroids as natural ligands of mouse pheromone-sensing neurons. J. Neurosci. 28, 6407-6418. doi: 10.1523/JNEUROSCI.1425-08.2008

Olender, T., Lancet, D., and Nebert, D. W. (2008). Update on the olfactory receptor (OR) gene superfamily. Hum. Genomics 3, 87-97. doi: 10.1186/14797364-3-1-87

Olender, T., Waszak, S. M., Viavant, M., Khen, M., Ben-Asher, E., Reyes, A., et al. (2012). Personal receptor repertoires: olfaction as a model. BMC Genomics 13:414. doi: 10.1186/1471-2164-13-414

Olson, M. V. (1999). When less is more: gene loss as an engine of evolutionary change. Am. J. Hum. Genet. 64, 18-23. doi: 10.1086/302219
Pantages, E., and Dulac, C. (2000). A novel family of candidate pheromone receptors in mammals. Neuron 28, 835-845. doi: 10.1016/s0896-6273(00) 00157-4

Park, S. H., Podlaha, O., Grus, W. E., and Zhang, J. (2011). The microevolution of V1r vomeronasal receptor genes in mice. Genome Biol. Evol. 3, 401-412. doi: 10. 1093/gbe/evr039

Perret, M. (1996). Manipulation of sex ratio at birth by urinary cues in a prosimian primate. Behav. Ecol. Sociobiol. 38, 259-266. doi: 10.1007/s0026500 50241

Perret, M. (2005). Relationship between urinary estrogen levels before conception and sex ratio at birth in a primate, the gray mouse lemur. Hum. Reprod. 20, 1504-1510. doi: 10.1093/humrep/deh802

Perret, M., Aujard, F., Séguy, M., and Schilling, A. (2003). Olfactory bulbectomy modifies photic entrainment and circadian rhythms of body temperature and locomotor activity in a nocturnal primate. J. Biol. Rhythms 18, 392-401. doi: 10. 1177/0748730403254248

Perret, M., and Schilling, A. (1995). Sexual responses to urinary chemosignals depend on photoperiod in a male primate. Physiol. Behav. 58, 633-639. doi: 10. 1016/0031-9384(95)00112-y

Petrulis, A. (2013a). Chemosignals and hormones in the neural control of mammalian sexual behavior. Front. Neuroendocrinol. 34, 255-267. doi: 10.1016/j. yfrne.2013.07.007

Petrulis, A. (2013b). Chemosignals, hormones and mammalian reproduction. Horm. Behav. 63, 723-741. doi: 10.1016/j.yhbeh.2013.03.011

Pfister, P., and Rodriguez, I. (2005). Olfactory expression of a single and highly variable V1r pheromone receptor-like gene in fish species. Proc. Natl. Acad. Sci. US A 102, 5489-5494. doi: 10.1073/pnas.0402581102

Poux, C., and Douzery, E. J. (2004). Primate phylogeny, evolutionary rate variations and divergence times: a contribution from the nuclear gene IRBP. Am. J. Phys. Anthropol. 124, 1-16. doi: 10.1002/ajpa.10322

Rodriguez, I., Del Punta, K., Rothman, A., Ishii, T., and Mombaerts, P. (2002). Multiple new and isolated families within the mouse superfamily of V1r vomeronasal receptors. Nat. Neurosci. 5, 134-140. doi: 10.1038/ nn795

Rodriguez, I., Greer, C. A., Mok, M. Y., and Mombaerts, P. (2000). A putative pheromone receptor gene expressed in human olfactory mucosa. Nat. Genet. 26, 18-19. doi: 10.1038/79124

Rushmore, J., Leonhardt, S. D., and Drea, C. M. (2012). Sight or scent: lemur sensory reliance in detecting food quality varies with feeding ecology. PLoS One 7:e41558. doi: 10.1371/journal.pone.0041558

Sánchez-Andrade, G., and Logan, D. W. (2014). Deconstructing pheromonemediated behavior one layer at a time. BMC Biol. 12:33. doi: 10.1186/1741-7007$12-33$

Schilling, A., Serviere, J., Gendrot, G., and Perret, M. (1990). Vomeronasal activation by urine in the primate Microcebus murinus: a 2 DG study. Exp. Brain Res. 81, 609-618. doi: 10.1007/bf02423511

She, X., Cheng, Z., Zöllner, S., Church, D. M., and Eichler, E. E. (2008). Mouse segmental duplication and copy number variation. Nat. Genet. 40, 909-914. doi: 10.1038/ng.172

Shi, P., Bielawski, J. P., Yang, H., and Zhang, Y. P. (2005). Adaptive diversification of vomeronasal receptor 1 genes in rodents. J. Mol. Evol. 60, 566-576. doi: 10. 1007/s00239-004-0172-y

Springer, M. S., Meredith, R. W., Gatesy, J., Emerling, C. A., Park, J., Rabosky, D. L., et al. (2012). Macroevolutionary dynamics and historical biogeogrphy of primate diversification inferred from a species supermatrix. PLoS One 7:e49521. doi: 10.1371/journal.pone.0049521

Suárez, R., García-González, D., and de Castro, F. (2012). Mutual influences between the main olfactory and vomeronasal systems in development and evolution. Front. Neuroanat. 6:50. doi: 10.3389/fnana.2012.00050

Suendermann, D., Scheumann, M., and Zimmermann, E. (2008). Olfactory predator recognition in predator-naive gray mouse lemurs (Microcebus murinus). J. Comp. Psychol. 122, 146-155. doi: 10.1037/0735-7036.122.2.146

Vamathevan, J. J., Hasan, S., Emes, R. D., Amrine-Madsen, H., Rajagopalan, D., Topp, S. D., et al. (2008). The role of positive selection in determining the molecular cause of species differences in disease. BMC Evol. Biol. 8:273. doi: 10 . 1186/1471-2148-8-273

Venkatakrishnan, A. J., Deupi, X., Lebon, G., Tate, C. G., Schertler, G. F., and Babu, M. M. (2013). Molecular signatures of G-protein-coupled receptors. Nature 494, 185-194. doi: 10.1038/nature11896 
Verrelli, B. C., Lewis, C. M., Stone, A. C., and Perry, G. H. (2008). Different selective pressures shape the molecular evolution of color vision in chimpanzee and human populations. Mol. Biol. Evol. 25, 2735-2743. doi: 10. 1093/molbev/msn220

Wang, G. D., Shi, P., Zhu, Z. H., and Zhang, Y. P. (2010a). More functional V1R genes occur in nest-living and nocturnal terricolous mammals. Genome Biol. Evol. 2, 277-283. doi: 10.1093/gbe/evq020

Wang, G. D., Zhu, Z. H., Shi, P., and Zhang, Y. P. (2010b). Comparative genomic analysis reveals more functional nasal chemoreceptors in nocturnal mammals than in diurnal mammals. Chinese Sci. Bull. 55, 3901-3910. doi: 10.1007/s11434010-4202-4

Wilkinson, R. D., Steiper, M. E., Soligo, C., Martin, R. D., Yang, Z., and Tavaré, S. (2011). Dating primate divergences through an integrated analysis of palaeontological and molecular data. Syst. Biol. 60, 16-31. doi: 10.1093/sysbio/ syq054

Wynn, E. H., Sanchez-Andrade, G., Carss, K. J., and Logan, D. W. (2012). Genomic variation in the vomeronasal receptor gene repertoires of inbred mice. BMC Genomics 13:415. doi: 10.1186/1471-2164-13-415

Yang, Z. (1998). Likelihood ratio tests for detecting positive selection and application to primate lysozyme evolution. Mol. Biol. Evol. 15, 568-573. doi: 10. 1093/oxfordjournals.molbev.a025957

Yang, Z., and dos Reis, M. (2011). Statistical properties of the branch-site test of positive selection. Mol. Biol. Evol. 28, 1217-1228. doi: 10.1093/molbev/msq303

Yang, Z., Nielsen, R., and Goldman, N. (2009). In defense of statistical methods for detecting positive selection. Proc. Natl. Acad. Sci. U S A 106:E95. doi: 10. 1073/pnas.0904550106

Yoder, A. D., Chan, L. M., dos Reis, M., Larsen, P. A., Campbell, C. R., Rasoloarison, R., et al. (2014). Molecular evolutionary characterization of a V1R subfamily unique to Strepsirrhine primates. Genome Biol. Evol. 6, 213-227. doi: 10 1093/gbe/evu006

Yoder, A. D., and Yang, Z. H. (2000). Estimation of primate speciation dates using local molecular clocks. Mol. Biol. Evol. 17, 1081-1090. doi: 10. 1093/oxfordjournals.molbev.a026389
Yoder, A. D., and Yang, Z. (2004). Divergence dates for Malagasy lemurs estimated from multiple gene loci: geological and evolutionary context. Mol. Ecol. 13, 757773. doi: 10.1046/j.1365-294x.2004.02106.x

Young, J. M., Kambere, M., Trask, B. J., and Lane, R. P. (2005). Divergent V1R repertoires in five species: amplification in rodents, decimation in primates and a surprisingly small repertoire in dogs. Genome Res. 15, 231-240. doi: 10. 1101/gr.3339905

Young, J. M., Massa, H. F., Hsu, L., and Trask, B. J. (2010). Extreme variability among mammalian V1R gene families. Genome Res. 20, 10-18. doi: 10.1101/gr. 098913.109

Young, J. M., and Trask, B. J. (2007). V2R gene families degenerated in primates, dog and cow, but expanded in opossum. Trends Genet. 23, 212-215. doi: 10. 1016/j.tig.2007.03.004

Zhao, H., Xu, D., Zhang, S., and Zhang, J. (2011). Widespread losses of vomeronasal signal transduction in bats. Mol. Biol. Evol. 28, 7-12. doi: 10 . 1093/molbev/msq207

Conflict of Interest Statement: The authors declare that the research was conducted in the absence of any commercial or financial relationships that could be construed as a potential conflict of interest.

Received: 16 October 2014; accepted: 25 November 2014; published online: 12 December 2014.

Citation: Yoder AD and Larsen PA (2014) The molecular evolutionary dynamics of the vomeronasal receptor (class 1) genes in primates: a gene family on the verge of a functional breakdown. Front. Neuroanat. 8:153. doi: 10.3389/fnana.2014.00153 This article was submitted to the journal Frontiers in Neuroanatomy.

Copyright (C) 2014 Yoder and Larsen. This is an open-access article distributed under the terms of the Creative Commons Attribution License (CC BY). The use, distribution and reproduction in other forums is permitted, provided the original author(s) or licensor are credited and that the original publication in this journal is cited, in accordance with accepted academic practice. No use, distribution or reproduction is permitted which does not comply with these terms. 